\title{
Article \\ In Situ Consolidation of Thermoplastic Prepreg by Generating Harmonic Oscillations on the Consolidation Roller
}

\author{
Mohammad Bahar*(D), Marco Brysch (D) and Michael Sinapius (D) \\ Institute of Mechanics and Adaptronics, Technical University of Braunschweig, Langer Kamp 6, \\ 38106 Braunschweig, Germany; m.brysch@tu-braunschweig.de (M.B.); m.sinapius@tu-braunschweig.de (M.S.) \\ * Correspondence: m.bahar@tu-braunschweig.de
}

Citation: Bahar, M.; Brysch, M.; Sinapius, M. In Situ Consolidation of Thermoplastic Prepreg by Generating Harmonic Oscillations on the Consolidation Roller. J. Compos. Sci. 2022, 6, 1. https://doi.org/10.3390/ jcs6010001

Academic Editor: Francesco

Tornabene

Received: 19 November 2021

Accepted: 20 December 2021

Published: 21 December 2021

Publisher's Note: MDPI stays neutral with regard to jurisdictional claims in published maps and institutional affiliations.

Copyright: (C) 2021 by the authors. Licensee MDPI, Basel, Switzerland. This article is an open access article distributed under the terms and conditions of the Creative Commons Attribution (CC BY) license (https:// creativecommons.org/licenses/by/ $4.0 /)$.
Abstract: Automation technologies such as Automated Fiber Placement (AFP) or Automated Tape Laying (ATL) are widely used in the aerospace industry today. However, these processes can still be further improved for higher productivity. Fiber-reinforced plastics allow the production of components with extremely high specific strength and stiffness. Regarding the automated manufacturing processes, the thermoplastic tape placement offers efficiency improvements compared to the nowadays more commonly used thermoset tape placement, especially through the substitution of the expensive and time-consuming autoclave process. The consolidation of thermoplastic Prepregs is achieved with an elastic or rigid roller according to the current state of the art. The Prepregs must be consolidated precisely on the substrate or on top of each other. The most important process parameters for high-quality laminate structure with low porosity are the control of heat source, consolidation force, consolidation roll speed, and tape tension. The efficiency of the AFP process can generally be improved by increasing the speed of the consolidation roller. By increasing the speed of the consolidation roller, porosity is increased and mechanical properties of the laminate are reduced significantly due to the short contact time between consolidation roller and Prepregs. This study investigates a process that can reduce these challenges by increasing the contact time and force duration of the consolidation roller on the Prepregs. The consolidation roller in this study is additionally to be driven by the harmonic oscillations. The new method allows the consolidation roller to oscillate forward and backward during the fiber placement process. This creates another force vector in addition to the compressive force of the consolidation roller and increases the bonding strength between the layers.

Keywords: automated fiber placement; in situ consolidation; harmonic oscillations; consolidation roller

\section{Introduction}

Composite materials are increasingly used in industrial applications as they allow components with extremely high specific strength and stiffness. For economical and qualitative aspects, a high degree of automation in the production of components is also desirable for these materials. Automated tape laying (ATL) and automated fiber placement (AFP) are the most commonly used Prepreg technologies [1].

These two processes are especially interesting for the aerospace industry, where high tolerances are required [2]. Thermoplastic or thermoset unidirectional (UD) Prepregs are increasingly used for the automated production of advanced high-performance composites [3]. The placement process with thermoset Prepregs requires a high effort on cleaning and maintenance, as well as the expensive and time-consuming hardening of the finished components in the autoclave. Compared to the thermoset tape laying process, the thermoplastic tape laying process has the potential to completely obviate the autoclave process, Figure 1. 


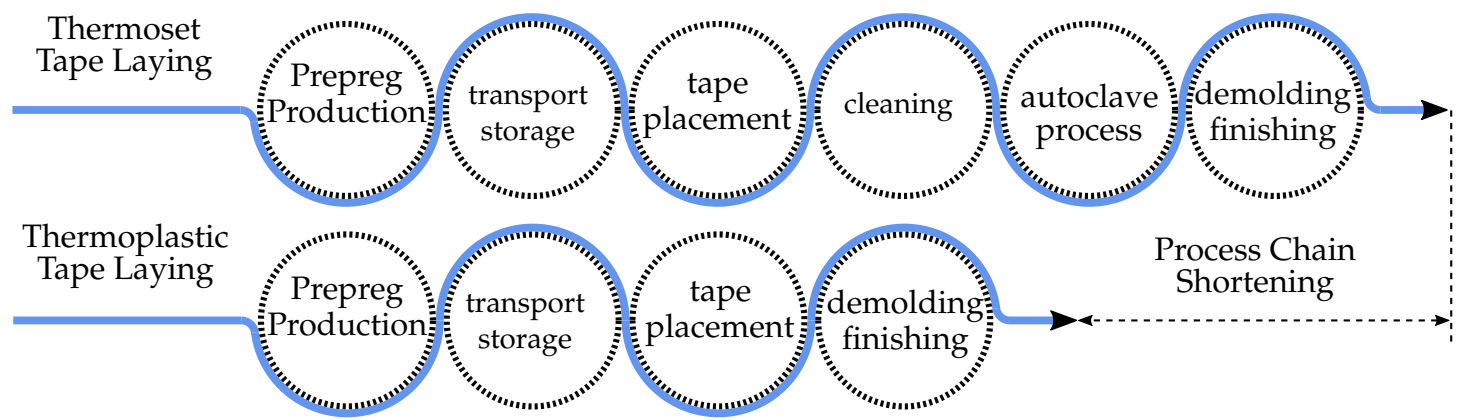

Figure 1. Process chain comparison of the thermoset and thermoplastic tape laying process.

The thermoplastic matrix system can solidify in a few seconds, during processing, by cooling at room temperature [1,4]. The principle of this process is illustrated in Figure 2. The consolidation roller applies fiber-reinforced, thermoplastic Prepreg in a defined way and presses it on the existing Prepregs. The thermoplastic matrix allows bonding, during tape deposition through heat application [5].

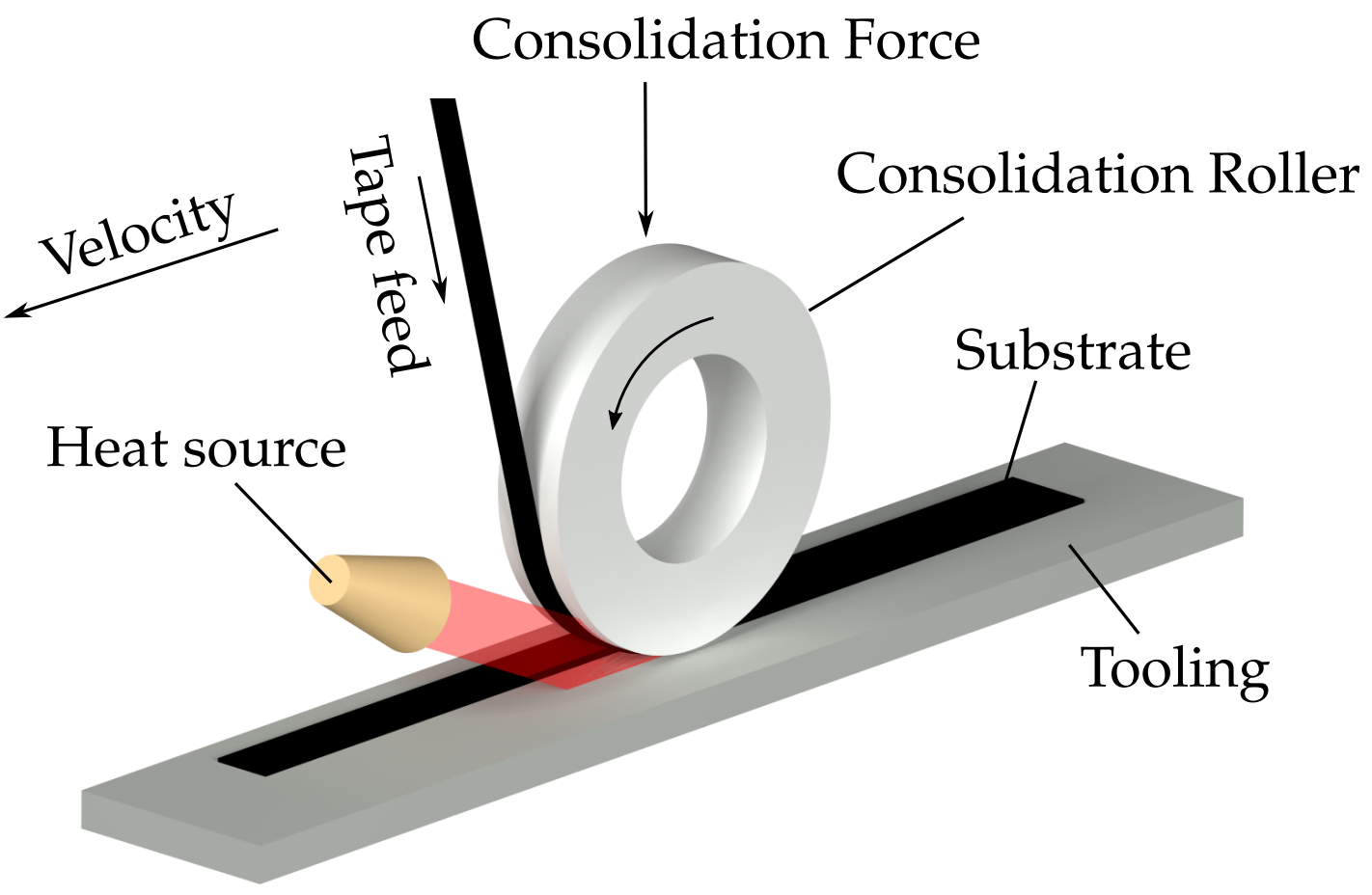

Figure 2. The principle of thermoplastic Automated Fiber Placement (AFP) process.

Despite the advantages of thermoplastic materials, this process is not widely used in the industry. The quality of the consolidation is often still inadequate, therefore an autoclave process has to be subsequently applied which destroys the economic advantage of the process [6]. Mechanically or thermally induced stresses lead to significant component deformation, especially in open structures [7]. Poor adhesion to the tool due to insufficient self-adhesive force leads to a secondary effect on concave geometries (Figure 3a). Placement on non-cylindrical surfaces can lead to some gaps [8]. In the case of thermoset tape laying, these can be filled by hand with specially cut pieces, which is not possible with thermoplastic tape laying (Figure 3b). 


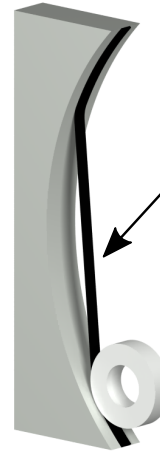

(a)
Secoundary effect

Gap formation

Forced laid down tape

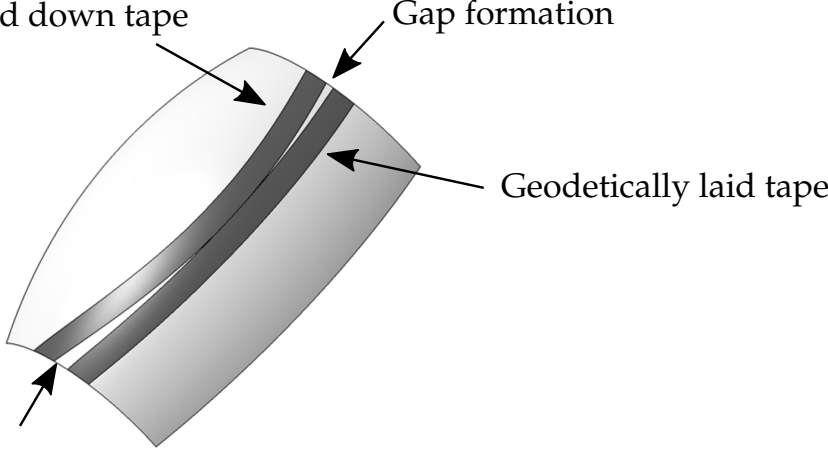

(b)

Figure 3. secoundary effect through poor adhesion of the tape (a) , Gap creation through forced paths (b).

Placement of convex or concave parts with rigid consolidation roller can tilt the tape and lead to irregular compaction of the tape (Figure 4 right).

The thermoplastic Prepregs are compacted according to the state of the art by a roller system with three different types. The first is a rigid consolidation roller that consists of a specific steel cylinder with internal cooling channels. The second consolidation roller consists of a similar basic structure and is additionally covered with a thick silicone shell to ensure shape adaptation. This method is often used in the industry. The consolidation tire as the third type is a special construction based on the basic structure of a car tire. A reinforced silicone shell is connected to a steel shaft with internal pressure. The internal pressure of the tire is adjusted and constantly regulated via inlet and outlet channels. A scientific study compared these three different consolidation rollers with each other in different aspects [9]. It shows that the form-adaptive consolidation roller presents significant advantages over the other concepts [10]. It considerably increases the layer contact length compared to the rigid roller and the roller with silicone cover, as can be seen in Figure 4 on the left. Additionally, at high placement speeds, it significantly increases the layer contact time.
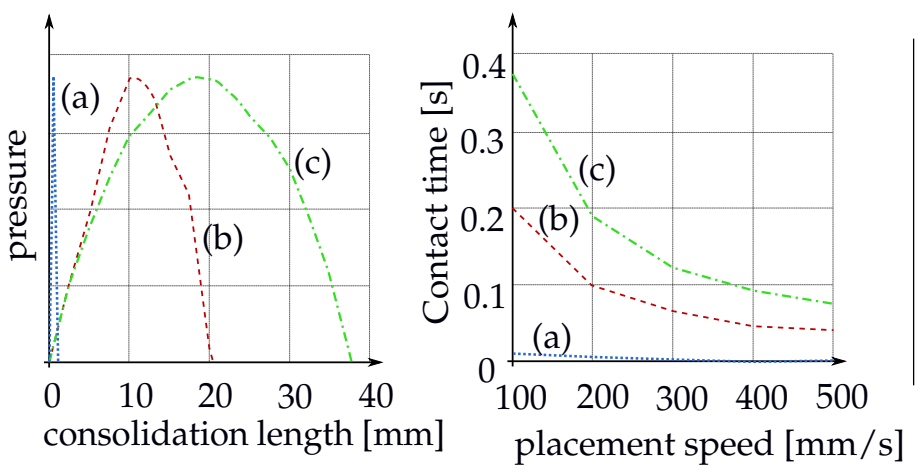

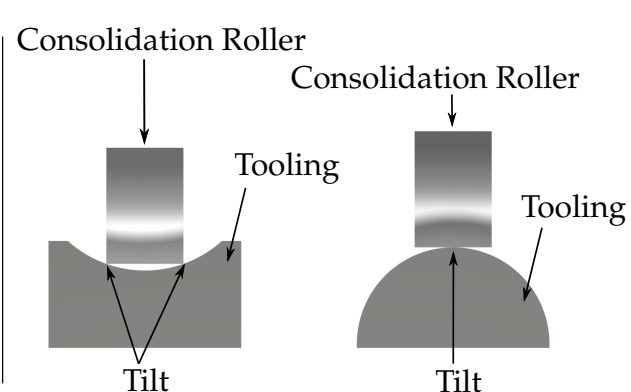

(D)

(E)
(a)
rigid roller
(b) -anible roller
(c) -.-.- form-adaptive roller

Figure 4. Consolidation lengths of the different rollers and contact times (left). Tilting of the consolidation roller on concave (D) and convex (E) surfaces (right).

The rigid consolidation (a) is often used when the tool shape is flat. When the tool shape is curved, especially for concave surfaces, the flexible roller (b) can be used very well. For complex double curved surfaces, the form-adaptive roller (c) can be used most effectively, although controlling the air pressure of the rollers is a challenge. The diagram in Figure 4 on the left, the contact time between the consolidation roller and the materials is significantly reduced at high speed. By increasing the contact time, even at low speeds, the 
quality of the laminate can be improved and the advantage of this process can be better displayed. The viscosity of the thermoplastic material during processing depends inversely on the process temperature. Low viscosity is required to achieve high bonding strength. Temperature and exposure time must not be too high, as degradation effects can occur which impair the mechanical properties of the bonding [11].

An important parameter for high laminate quality is consolidation force. The force generated by the consolidation unit fills voids and gaps between the tape layers. The proportion of interfaces in direct contact increases with increasing consolidation force. At these interfaces, intramolecular adhesive forces can occur, which are decisive for interlaminar strength. Several research studies have shown that too much consolidation force has a negative influence on the adhesive strength $[5,12]$. The consolidation time, with which the layers are compressed by the consolidation unit is also an important parameter. The longer the contact time of the layer, the more connections can build up between the layers, and the higher the bonding strength [9].

Consequently, one company (Cincinnati) has developed a Planar Consolidation Unit. The unit can increase the contact time between the material and the consolidation unit. However, this process is very slow and can only be used for planar laminates. [13].

At the Technical University of Munich (TUM), a $4 \mathrm{KW}$ diode laser is used for in situ consolidation of PEEK material. The aim of this research is to increase the laminate structure by parameter optimization in the AFP process [14]. In further investigations, researchers tried to increase the quality of the laminates by different parameterization of the laydown speed and compaction force as well as the melting temperature $[15,16]$. AFP was widely used in the industry for several years and many publications regarding the consolidation unit are published. However, publications are mostly concerned with the materials and cooling of the consolidation unit. Recently, a research paper was published that experimentally investigated an approach to improve compaction quality in a preheated in situ compaction process by applying ultrasonic vibration. The consolidation time is also increased in this paper in order to improve the quality of the laminates [17]. This research suggests a new principle of motion based on a consolidation roller.

\section{Methodology}

The aim of this research is to increase the laminate quality without reducing the depositing speed by keeping the same depositing parameters. This goal is achieved by generating new deposit forces on the consolidation roll. High-speed forward and reverse rotation of the consolidation roller generates new shear force vectors and increases the force duration on the laminate, as well as extending the contact time of the consolidation roller and tape at the same deposit speed. These shear forces are applied in the fiber direction and, by tensioning the fiber during laydown, the fiber waviness is eliminated. Furthermore, the compaction force of the roller remains constant over time perpendicular to the fiber direction. These additional force vectors can be generated by the generation of harmonic oscillations that are connected to the consolidation roller. While harmonic oscillations are sinusoidal, non-harmonic are all oscillations whose shape does not correspond to a sine wave [18]. The oscillations are generated by two unbalanced masses that rotate in the same direction, but their phase is shifted by $180^{\circ}$, and the whole oscillator is connected to the shaft of the consolidation roller (Figure 5 left). It is essential that the unbalanced masses are mounted rotated by $180^{\circ}$ to each other, as in this arrangement a harmonic oscillation can be generated. If the unbalanced masses are mounted without the $180^{\circ}$ rotation, each rotation will cause the roller to knock or pop off the tooling plate, causing the laminate surfaces to be damaged and the fibers to fail to be consolidated parallel to each other. 


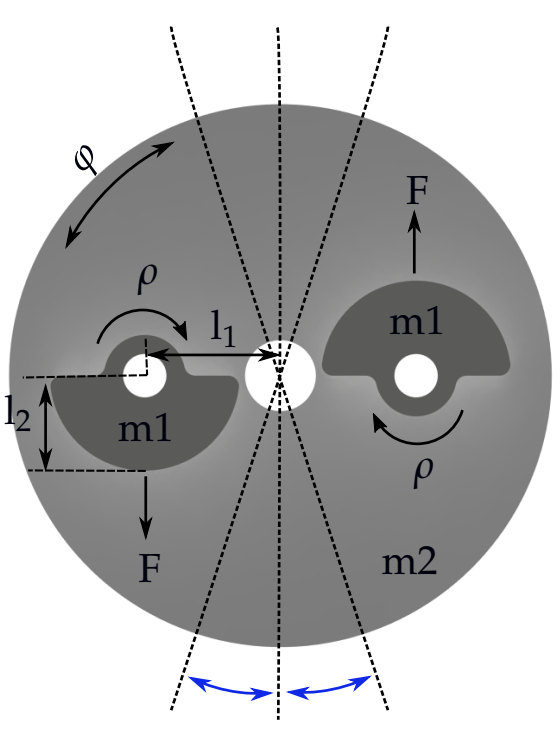

Oscillatory Vibration

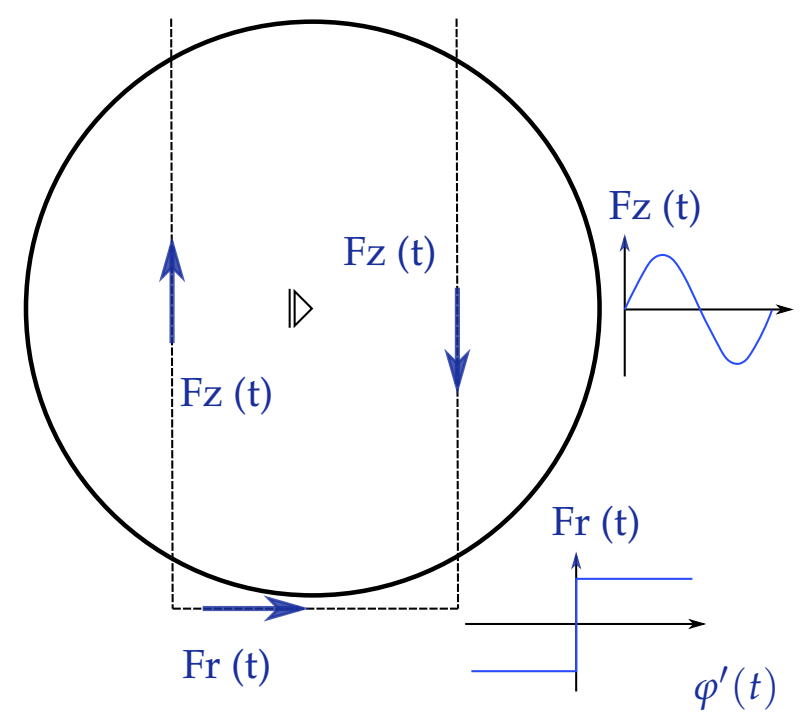

Figure 5. Consolidation roller with oscillating vibration (left), time force progressions (right).

The consolidation roller on the AFP machine is usually compact and cannot install the unbalanced masses directly on the roller considering the mechanism movements. Furthermore, this mechanism can collide with other components. Therefore, initially, it is necessary to define a basic setting for the installation and the parameters in detail.

The position of $l_{1}$ lever arm and $l_{2}$ mass length are the most important parameters for the whole system. The centrifugal forces $F_{Z}$ of the unbalanced masses generate the drive torque of the roller. They are rotating force vectors and their force application points rotate additionally with the roller. The resultant force $F_{Z}$ is zero at every time, as the forces are always of equal value and apply in opposite directions. Therefore, only the effect of the forces $F_{Z}$ for the drive torque must be considered. The components of the forces $F_{Z}$ applying tangentially to the consolidation roller are exclusively responsible for the drive torque (Figure 5 right). This component $F_{Z}(t)$ is simply the projection of the circular motion of $\mathrm{Fz}$ and thus a sinusoidal oscillation. The circulating force vectors can therefore be reduced to two forces $F_{Z}(t)$ tangentially applied to the roller with a sinusoidal shape. The rotation of the force application points also has no influence on the drive torque, as the lever arms of $F_{Z}(t)$ always remain the same.

As the roller executes an alternating torsional vibration, it applies a time-dependent frictional force $F_{r}(t)$ to the substrate. Depending on the direction of rotation of the roller, this changes its direction and thus its sign. Depending on the angular velocity of the roller, the following physical effects must be identified for the frictional force:

- $\quad$ Static friction, when the angular velocity is zero.

- $\quad$ Sliding friction, which exists above a certain angular velocity.

- A transition area between static and sliding friction. Here, the stick-slip effect can occur, which is also known as jerk sliding. In this case, static and sliding friction occur alternately, causing the component to perform a sudden jerky movement.

The static frictional force is generally greater than the dynamic frictional force. The frictional force $F_{r}(t)$ depends on the normal force $F_{n}$ and the coefficient of sliding friction $\mu$.

In addition, as described above, the space required by the unbalanced masses and the oscillator extends beyond the diameter of the consolidation roller. To prevent the unbalanced masses from colliding with the other components on which the consolidation roller stands, the oscillator must be physically separated from the roller. The oscillator can be used next to the consolidation roller or on a separate shaft. 


\section{Imbalance Exciter-ODE Modeling}

The system of the consolidation roller consists of three elements as shown in Figure 6. These are the consolidation roll with lever arm $l_{1}$ to the oscillating masses $m_{a}$ and $m_{c}$. The consolidation roll is considered massless and borne in its center point $x=0$ and $y=0$. The constellation of the elements can be described with three angles, $\alpha, \gamma$, and $\varphi$. Here, the roller position is given by $\varphi$, where $\varphi$ is measured to the horizontal through the bearing point. The rotational speed of the consolidation roll is therefore given by $\dot{\varphi}$.

The center of rotation of the two masses $m_{a}$ and $m_{c}$ is at angle $\alpha$ to the horizontal through the bearing center of the consolidation roll. Analogously, the center of mass of the rotational masses is determined by $\gamma$ and the lever arm $l_{2}$. Hence, the rotational speed of the oscillating masses is given by $\dot{\gamma}$. The angular velocities and position are known at a given time $t$. In the positive and negative direction of the axes, the distance $x, y$ or $x^{\prime}, y^{\prime}$, respectively, can be derived from the geometric conditions. These can be described by the transformation equations:

$$
\begin{aligned}
x & =l 1 \cdot \cos (\varphi(t))+l 2 \cdot \cos (\gamma(t)) \\
y & =l 1 \cdot \sin (\varphi(t))+l 2 \cdot \sin (\gamma(t)) \\
x^{\prime} & =l 1 \cdot \cos \left(\varphi(t)+180^{\circ}\right)+l 2 \cdot \cos (\gamma(t)) \\
y^{\prime} & =l 1 \cdot \sin \left(\varphi(t)+180^{\circ}\right)+l 2 \cdot \sin (\gamma(t))
\end{aligned}
$$

Physical model of the consolidation roller is based on the formulation of the centrifugal force of mass $m_{a}$ and $m_{c}$. As the masses $m_{a}$ and $m_{c}$ are equal, it follows that $m=m_{a}=m_{\mathcal{c}}$. The radius $r(t)$ is defined as the distance between the bearing $B$ and the center of mass for $m_{a}$ and $m_{c}$. It follows that $r(t)=\sqrt{x^{2}+y^{2}}$ and equivalently $r^{\prime}(t)=\sqrt{x^{\prime 2}+y^{\prime 2}}$. For simplicity, the time dependence of $\mathrm{r}(\mathrm{t})$ is omitted in the following formulations $r=r(t)$.

$$
\begin{aligned}
F_{a} & =r \cdot m \cdot \omega^{2} \\
& =r \cdot m \cdot\left(\frac{d \alpha}{d t}\right)^{2} \\
F_{c} & =r \cdot m \cdot \omega^{2} \\
& =r \cdot m \cdot\left(\frac{d \alpha^{\prime}}{d t}\right)^{2}
\end{aligned}
$$

The angles $\alpha$ and $\alpha^{\prime}$ are given respectively by

$$
\begin{aligned}
\alpha & =\arctan \left(\frac{y}{x}\right) \\
\alpha^{\prime} & =\arctan \left(\frac{y^{\prime}}{x^{\prime}}\right) .
\end{aligned}
$$

With Equations (1) and (2) in Equation (7), and Equations (3) and (4) in Equation (8), one obtains:

$$
\begin{array}{r}
\alpha=\arctan \left(\frac{l 1 \cdot \sin (\varphi(t))+l 2 \cdot \sin (\gamma(t))}{l 1 \cdot \cos (\varphi(t))+l 2 \cdot \cos (\gamma(t))}\right) \\
\alpha^{\prime}=\arctan \left(\frac{l 1 \cdot \sin \left(\varphi(t)+180^{\circ}\right)+l 2 \cdot \sin (\gamma(t))}{l 1 \cdot \cos \left(\varphi(t)+180^{\circ}\right)+l 2 \cdot \cos (\gamma(t))}\right) .
\end{array}
$$

The time derivative and squaring of the Equations (9) and (10) followed by substitution into (5) and (6) results in: 


$$
\begin{aligned}
F_{a} & =r \cdot m \frac{\left.\left(l_{1} l_{2} \cos (\varphi-\gamma)+l_{1}^{2}\right) \dot{\varphi}+l_{1} l_{2} \sin (\varphi) \sin (\gamma) \dot{\gamma}+l_{1} l_{2} \cos (\varphi) \cos (\gamma) \dot{\gamma}+l_{2}^{2} \dot{\gamma}\right)^{2}}{\left(2 l_{1} l_{2}(\cos (\varphi-\gamma))+l_{2}^{2}+l_{1}^{2}\right)^{2}} \\
F_{c} & =r \cdot m \frac{\left(\left(l_{1} l_{2} \sin (\gamma)(\dot{\varphi}+\dot{\gamma}) \sin \left(\varphi+180^{\circ}\right)+l_{1} l_{2} \cos (\gamma)(\dot{\varphi}+\dot{\gamma}) \cos \left(\varphi+180^{\circ}\right)+l_{1}^{2} \dot{\varphi}+l_{2}^{2} \dot{\gamma}\right)^{2}\right.}{\left(2 l_{1} l_{2} \cos \left(\varphi-\gamma+180^{\circ}\right)+l_{2}^{2}+l_{1}^{2}\right)^{2}}
\end{aligned}
$$

which can be divided into the $x$ and $y$ portions. The forces at bearing point $B$ are therefore calculated with the equilibrium of forces:

$$
\begin{aligned}
F_{B x} & =-F_{a x}+F_{c x} \\
& =-F_{a} \cos \left(\arctan \left(\frac{y}{x}\right)\right)+F_{c} \cos \left(\arctan \left(\frac{y^{\prime}}{x^{\prime}}\right)\right) \\
& =-F_{a} \frac{x}{\sqrt{y^{2}+x^{2}}}+F_{c} \frac{x^{\prime}}{\sqrt{x^{\prime 2}+y^{\prime 2}}} \\
F_{B y} & =-F_{a y}+F_{c y} \\
& =-F_{a} \sin \left(\arctan \left(\frac{y}{x}\right)\right)+F_{c} \sin \left(\arctan \left(\frac{y^{\prime}}{x^{\prime}}\right)\right) \\
& =-F_{a} \frac{y}{\sqrt{y^{2}+x^{2}}}+F_{c} \frac{y^{\prime}}{\sqrt{x^{\prime 2}+y^{\prime 2}}}
\end{aligned}
$$

As shown in Figure 6 the $y$-part of the bearing forces is equal to the compressive force $F_{z}(t)=F_{b y}(t)$ and the $x$-portion is equal to the shear force $F_{r}(t)=F_{b x}(t)$.

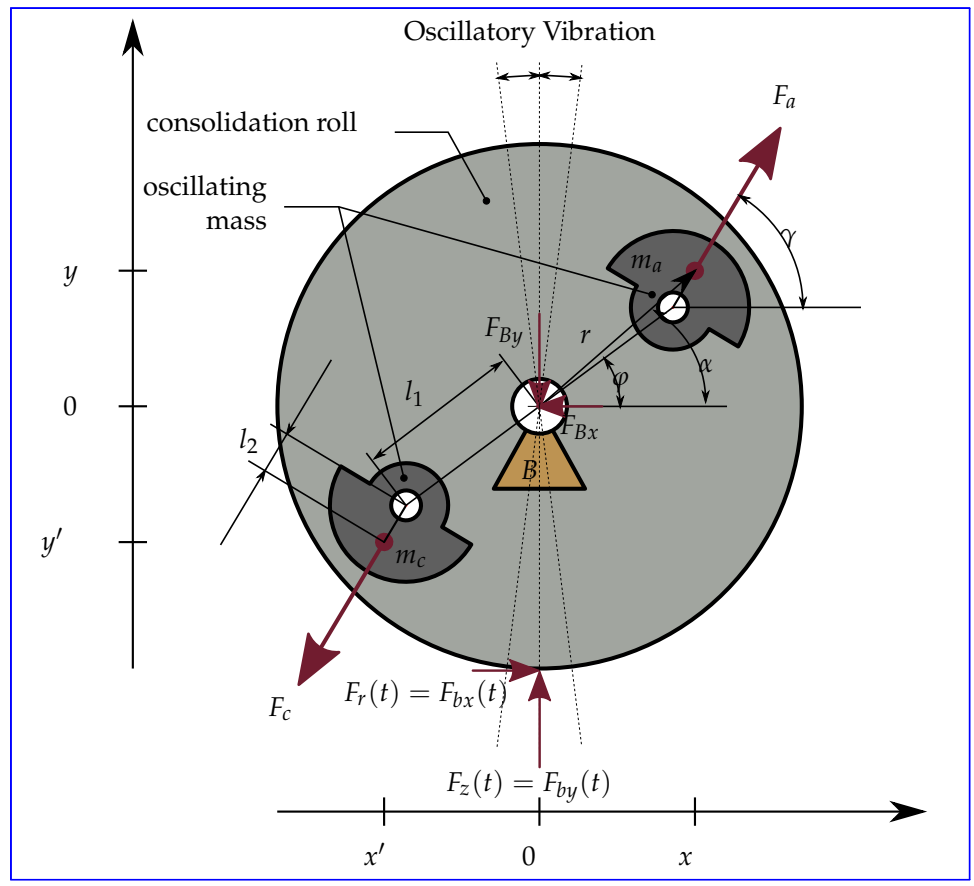

Figure 6. Consolidation roller with oscillating vibration caused by the oscillating masses around the moving consolidation roll.

A set of parameters was chosen to simulate the behavior of the consolidation system using the derived model from Equations (1)-(14). The simulation should show which forces can occur in $x$ - and $y$-direction and how the influence of $\dot{\varphi}=U_{0}$ and $\dot{\gamma}=U_{1}$ relates.

The following model parameters have been used for the simulation:

The first simulation covers the time behavior of forces in the $x$ - and $y$-direction. Forces depend on the angular velocities $U_{0}$ and $U_{1}$. To show the effect of $U_{0}$ and $U_{1}$, each was 
varied in a range of $U_{0}=\{0.5,1\}$ and $U_{1}=\{50,100\}$. The time period was chosen to be $120 \mathrm{~s}$. As can be seen from the Figure $7, U_{0}$ essentially influences the fundamental, and $U_{1}$ the harmonic, oscillations.

\begin{tabular}{llll}
\hline Model Parameter & Value & Unit & Description \\
\hline$U_{0}$ & $0-40$ & $\mathrm{U} / \mathrm{min}$ & (initial) value for $\dot{\varphi}$ \\
$U_{1}$ & $200-900$ & $\mathrm{U} / \mathrm{min}$ & (initial) value for $\dot{\gamma}$ \\
$\mathrm{m}$ & 0.08 & $\mathrm{~kg}$ & vibration masses $m_{a}$ \\
11 & 0.06 & $\mathrm{~m}$ & and $m_{c}$ \\
12 & 0.035 & $\mathrm{~m}$ & length of lever arm r1 \\
$\Delta t$ & 0.001 & $\mathrm{~s}$ & length of lever arm r2 \\
& & & timestep in \\
simulation
\end{tabular}
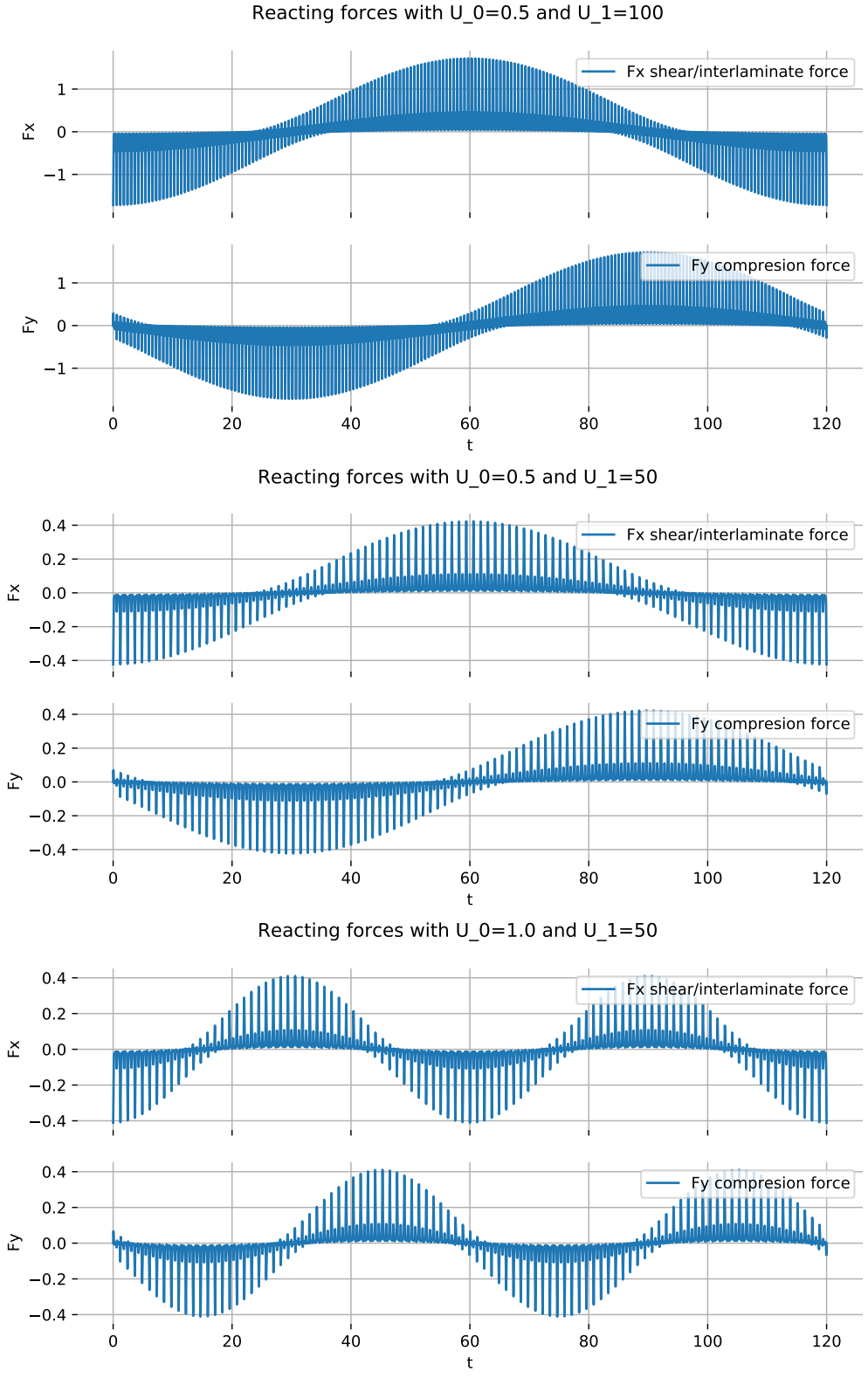

Figure 7. Simulated forces between the consolidation roll and laminate in the $x$ - and $y$-directions $\left(F_{r}, F_{z}\right)$ as a function of time $\mathrm{t}=0-120 \mathrm{~s}$. The three graphs indicate that $U_{0}$ influences the fundamental, and $U_{1}$ the harmonic, oscillations. 
The forces acting on the system are significant for the effect of the consolidation roll. For this purpose, a combination of different $U_{0}=0.1,0.15,0.3,0.5,1.0$, and 1.5 and $U_{1}=200,300,400,500,600,700,800$, and 900 was simulated, and the largest occurring force was noted in each case is shown in Figure 8. The simulation results show that, as the value of $U_{0}$ increases, there is initially a rise in $F_{x}$ and $F_{y}$. The maximum forces reach a high point at $U_{0 \max } \approx 0.5$. Values above $U_{0 \max }>0.5$ cause a slow decrease in maximum forces.
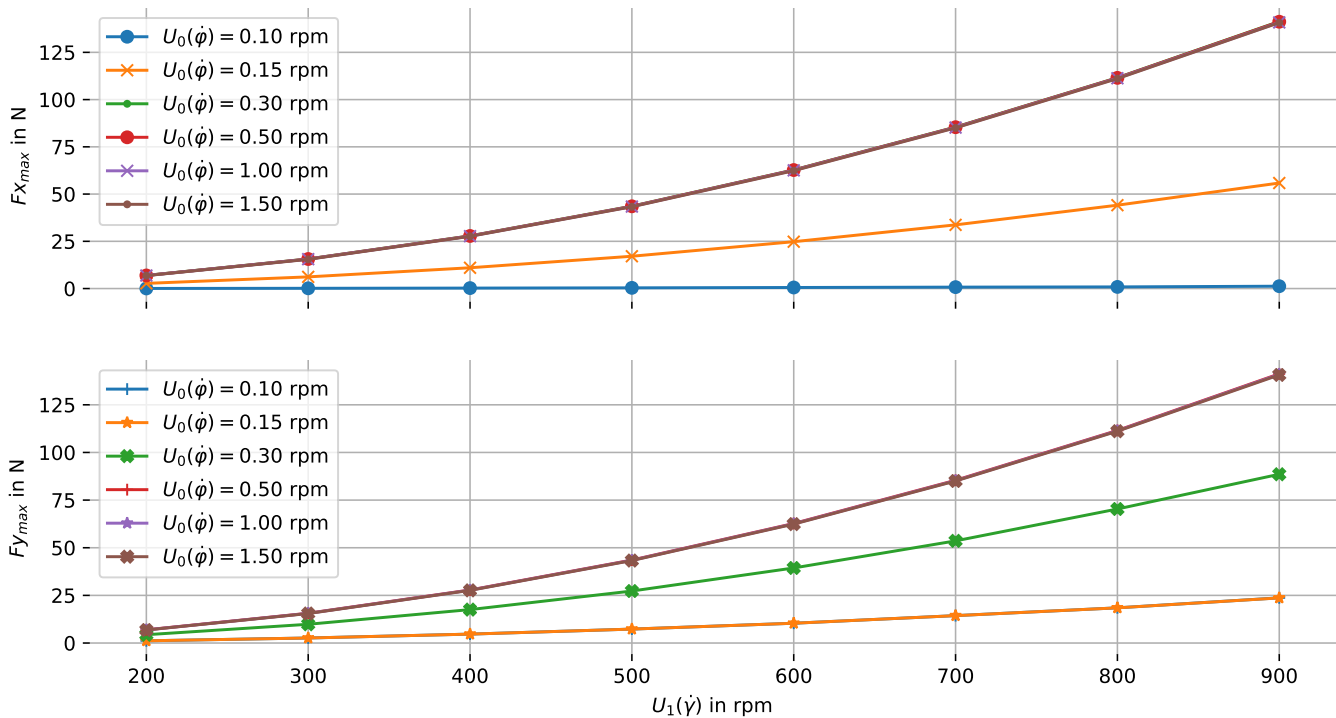

Figure 8. Expected maximum forces in $x$ - and $y$-directions $\left(F_{r}, F_{z}\right)$ with different mass velocity $\dot{\gamma}=200-900 \mathrm{U} / \mathrm{min}^{-1}$ depending on the consolodation roll velocity $\dot{\varphi}=0-40 \mathrm{U} / \mathrm{min}^{-1}$.

Figure 9 shows the maximum force $F_{x}$ and $F_{y}$ as a function of $U_{0}$ with constant $U_{1}$. It can be seen that $F_{x}$ reaches a maximum with $U_{0}=0.3$ and $F_{y}$ a maximum with $U_{0}=0.5$. Maximum forces are therefore obtained with a $U_{0} \approx 0.5$. Higher values reduce the maximum forces continuously by a small amount. The optimal operating point $U_{0 \max }$ is mainly determined by the geometry $l 1$ and $l 2$ of the consolidation system.
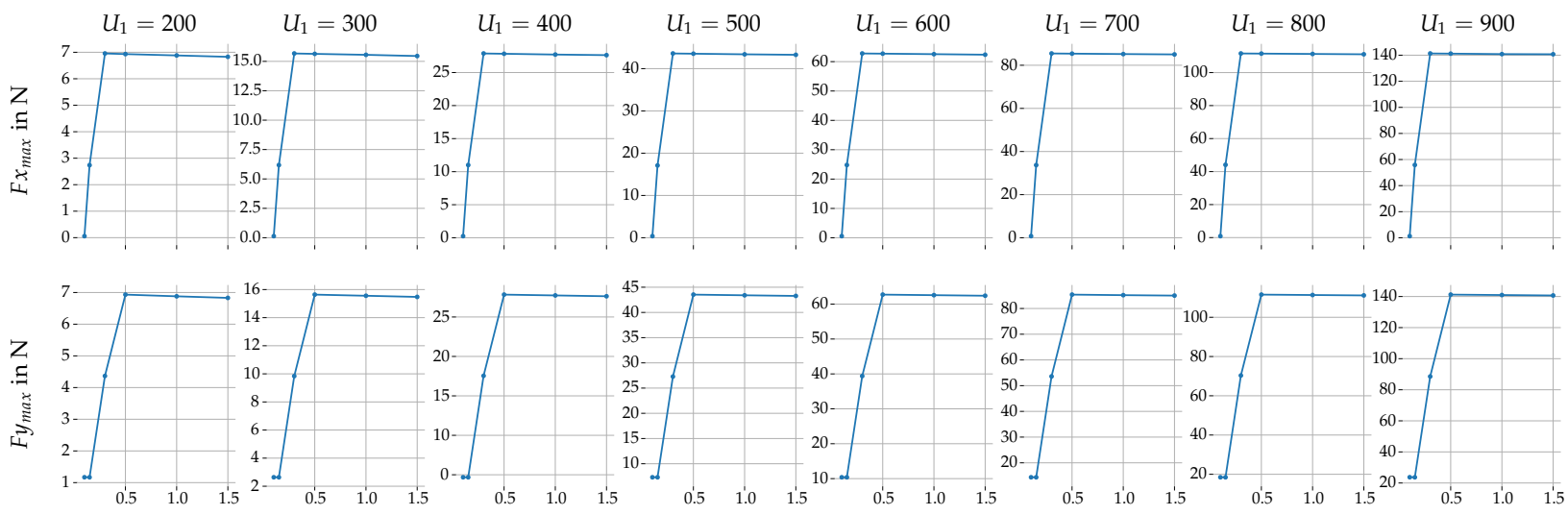

$U_{0}(\dot{\varphi})$ in rpm

Figure 9. With a value of $U_{0 \max } \approx 0.5, F_{x}$ and $F_{y}$ reach a relative maximum with increasing values of $U_{0}$, the maximum force, in $x$ and $y$, then decreases slightly again. The maximum point $U_{0 \max }$ is mainly determined by the geometry $l_{1}$ and $l_{2}$ of the consolidation system.

\section{Experimental Setup}

The unbalanced masses can be adjusted using a shaft on the consolidation roller in a compact configuration. The illustration shows the basic structure of the test platform (Figure 10b). The installation should provide measurement of the lateral force generated 
by the roller. A force sensor, which can measure in the tensile and compressive directions, is connected to a movable measuring carriage to which the roller transmits its shear force (Figure 10a). The roller should also be able to move back and forth in a linear guide, and its pressure force on the substrate should be adjustable. The consolidation roller is mounted on a vertical linear guide which can be loaded with weights.

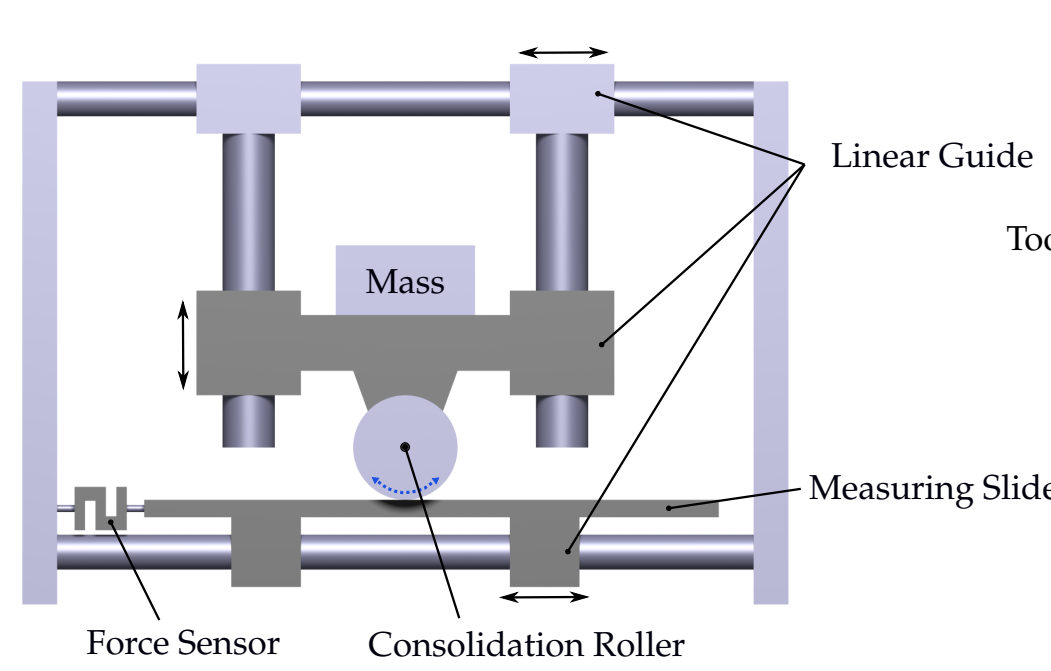

(a)
Consolidation Roller

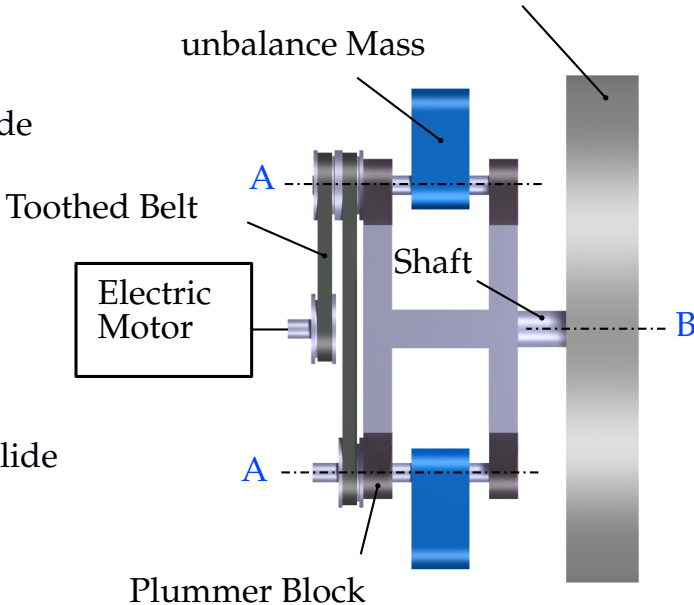

(b)

Figure 10. Drive of the unbalanced masses by toothed belts.

The main challenge in the design of the oscillator is the transfer of the drive power for the rotation of the unbalanced masses to the consolidation roller of the moving system. If the electric motor is installed directly on the moving oscillator, it is not simple to power the motor by rotating the roller. Therefore, a solution (Figure 10b) is required which allows the unbalanced masses to be driven by an external electric motor using a mechanical coupling. The system is very similar to a planetary gear. The two rotating shafts (A) which carry the unbalanced masses, are connected to an electric motor by toothed belt. This causes the unbalanced masses to rotate, which in turn induces rotation of the shaft $B$ and therefore of the oscillator and the roller. The toothed belt can also generate a direct rotation of the shaft B. Furthermore, coupling effects can occur, as a torsional oscillation of shaft B, in turn causes an angle change between the oscillator and the shaft of the electric motor.

The unbalanced masses should be able to rotate at a frequency of 3-8 Hz. As the transmission ratio of the selected timing belt drive is $1: 1$, the electric motor must be adjustable from $200-500 \mathrm{rpm}$. The moment must also be higher than the friction moment of the timing belt drive and the plain bearings.

The study evaluates how the mechanical Prepreg properties of composite materials change according to the new consolidation system. ILSS test can refer to the quality of the interlaminar bond by indicating the maximum shear stress existing between the laminate layers [19]. The investigated laminates material is the C T50-4.0/240-T140 from SGL Group unidirectional carbon fiber reinforced polyamide 6 . They are provided as a tape of 6.35 $\mathrm{mm}$ wide and $0.18 \mathrm{~mm}$ thickness. The parameters used to manufacture laminates are summarized in Table 1.

Table 1. Summary of the process parameters.

\begin{tabular}{lllllll}
\hline $\begin{array}{l}\text { Consolidation } \\
\text { Force }\end{array}$ & $\begin{array}{l}\text { Lay-Up } \\
\text { Velocity }\end{array}$ & $\begin{array}{l}\text { Torch } \\
\text { Temperature }\end{array}$ & $\begin{array}{l}\text { Hot Air } \\
\text { Velocity }\end{array}$ & $\begin{array}{l}\text { Lay-Up } \\
\text { Temperature }\end{array}$ & Tape Tension & $\begin{array}{l}\text { Tool } \\
\text { Temperature }\end{array}$ \\
\hline $150 \mathrm{~N}$ & $0.4 \mathrm{~m} / \mathrm{min}$ & $524^{\circ} \mathrm{C}$ & $4.5 \mathrm{~m} / \mathrm{s}$ & $280^{\circ} \mathrm{C}$ & $6 \mathrm{~N}$ & $120^{\circ} \mathrm{C}$ \\
\hline
\end{tabular}


The test configuration is according to the standard for determination of the apparent interlaminar shear strength DIN EN 2563 [20]. Eight specimens have been prepared for each testing, and a load was applied with a constant displacement rate of $1 \mathrm{~mm} / \mathrm{min}$. The results of the interlaminar shear strength at different rotational speed of the consolidation roller, compared to those without additional rotational movement, are shown in Figure 11. The significant positive effect of the new forces on the bonding between the different layers can be seen. By increasing the motor speed to $500 \mathrm{rpm}$, the shear strength can be improved by $6.2 \%$ compared to conventional methods. Higher speeds are not investigated in this study, as the AFP head structure for this research could operate stably up to $500 \mathrm{rpm}$.

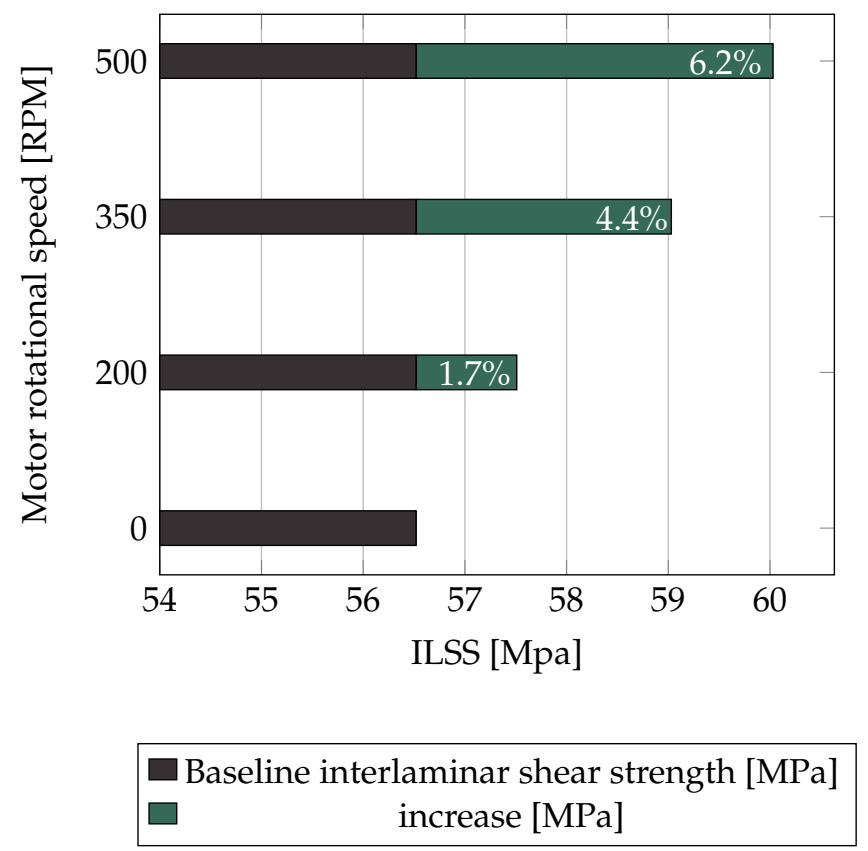

Figure 11. Increase in shear strength in \% compared to without oscillation.

\section{Conclusions}

The aim of this research is to produce higher mechanical properties in laminates by reducing the void content and improving the adhesive bonds of the Prepreg layers. Furthermore, pores weaken the bonding between the layers through their stress concentration. Especially in the compaction of thermoplastics, the pore content is usually high, as heat and force only apply to the joint for a short time. Torsional vibration of the consolidation roller can lead to a reduction in pore content during the bonding process, as the additional shear force introduced leads to shear movements between the tape layers. These could help the movement of the pores and therefore contribute to a reduction in pore content. In various experiments, the generation of oscillatory motion is identified to significantly improve the interlaminar shear strength in laminates. Due to the limited equipment, higher frequencies to find out the limit to increase interlaminar shear strength (ILSS) were not investigated. Finally, the simulations can show the appropriate parameters for optimized compacting of the laminate in terms of roller size and consolidation force. This study is specifically focused on the new system and further research is being conducted on different mechanical tests.

Author Contributions: M.B. (Mohammad Bahar) conceived, designed, and performed the experiments. M.B. (Marco Brysch) and M.S. commonly analyzed the data and wrote the paper. All authors have read and agreed to the published version of the manuscript.

Funding: The authors acknowledge the funding of the study by 'DFG'Deutsche Forschungsgemeinschaft. We acknowledge support by the German Research Foundation and the Open Access Publication Funds of the Technische Universität Braunschweig. 
Conflicts of Interest: The authors declare no conflict of interest.

\section{References}

1. Bahar, M.; Sinapius, M. Adaptive Feeding Roller with An Integrated Cutting System for Automated Fiber Placement (AFP). J. Compos. Sci. 2020, 4, 92. [CrossRef]

2. Grant, C. Automated processes for composite aircraft structure. Ind. Robot. Int. J. 2006, 33, 117-121. [CrossRef]

3. Denkena, B.; Schmidt, C.; Weber, P. Automated Fiber Placement Head for Manufacturing of Innovative Aerospace Stiffening Structures. Proced. Manuf. 2016, 6, 96-104. [CrossRef]

4. Rakhshbahar, M.; Sinapius, M. A Novel Approach: Combination of Automated Fiber Placement (AFP) and Additive Layer Manufacturing (ALM). J. Compos. Sci. 2018, 2, 42. [CrossRef]

5. Khaled, Y.; Mehdi, H. Processing of thermoplastic matrix composites through automated fiber placement and tape laying methods. J. Thermoplast. Compos. Mater. 2017, 31, 1676-1725.

6. Verstärkte, I. Handbuch Faserverbundkunststoffe/Composites-Grundlagen, Verarbeitung, Anwendungen, 4th ed.; Springer: Berlin/Heidelberg, Germany; New York, NY, USA, 2014.

7. Kermer-Meyer, A. Formhaltige und Komplexe Laminatstrukturen in Thermoplast-Tapelegeverfahren; RWTH Publications: Aachen, Germany, 2015.

8. Sawicki, A.; Minguet, P. The effect of intraply overlaps and gaps upon the compression strength of composite lami-nates. AIAA Struct. Dyn. Mater. 1998, 39, 1786.

9. Steyer, M. Laserunterstütztes Tapelegeverfahren zur Fertigung Endlosfaserverstärkter Thermoplastlaminate; Apprimus Wissenschaftsver: Aachen, Germany, 2013.

10. Dubratz, M. Laserunterstütztes Tape Placement Verfahren für Die Herstellung Dreidimensionaler Strukturkomponenten aus Endlosfaserverstärkten thermoplastischen Prepregs; Apprimus Wissenschaftsver: Aachen, Germany, 2015.

11. Lengsfeld, H.; Wolff-Fabris, F.; Krämer, J.; Lacalle, J.; Altstädt, V. Faserverbundwerkstoffe_Prepregs und ihre Verarbeitung; Carl Hanser Verlag GmbH Co KG: München, Germany, 2014.

12. Kollmannsberger, A.M. Heating Characteristics of Fixed Focus Laserassisted Thermoplastic-Automated FiberPlacement of 2D and 3D Parts. Ph.D. Thesis, Fakultät für Maschinenwesen, Technische Universität München, München, Germany, 2019.

13. Lamontia, M.; Gruber, M.; Waibel, B.; Cope, R.; Hulcher, A. Conformable Compaction System Used in Automated Fiber Placement of Large Composite Aerospace Structures; NASA Marshall Space Flight Center: Huntsville, AL, USA, 2002.

14. Engelhardta, R.; Ehardb, S.; Wolfa, T.; Oelhafenc, J.; Kollmannsbergera, A.; Drechslera, K. In Situ Joining of Unidirectional Tapes on Long Fiber ReinforcedThermoplastic Structures by Thermoplastic Automated Fiber Placement forScientific Sounding Rocket Applications. In Proceedings of the 2nd CIRP Conference on Composite Material Parts Manufacturing, Rotherham, UK, 10-11 November 2019.

15. Bandaru, A.K.; Clancy, G.; Peeters, D.; O’Higgins, R.M.; Weaver, P.M. Properties of a thermoplastic composite skin-stiffener interface in a stiffened structure manufactured by laser-assisted tape placement with in situ consolidation. Compos. Struct. 2019, 214, 123-131. [CrossRef]

16. Lukaszewicz, D.H.J.; Potter, K.D.; Eales, J. A concept for the in situ consolidation of thermoset matrix prepreg during automated lay-up. Compos. Part B Eng. 2013, 45, 538-543. [CrossRef]

17. Denkena, B.; Schmidt, C.; Kaczemirzk, M.; Schwinn, M. Influence of a Dynamic Consolidation Force on In Situ Consolidation Quality of Thermoplastic Composite Laminate. J. Compos. Sci. 2021, 5, 88. [CrossRef]

18. Gross, D.; Hauger, W.; Schröder, J.; Wall, W.A. Technische Mechanik 3-Kinetik; Springer: Berlin/Heidelberg, Germany; New York, NY, USA, 2015.

19. Mondo, J.; Parfrey, K. Performance of In Situ Consolidated Thermoplastic Composite Structure. Int. Sampe Tech. Conf. 1995, 27, 361-370.

20. DIN EN 2563. Aerospace Series—Carbon Fibre Reinforced Plastics-Unidirectional Laminates. Determination of Apparent Interlaminar Shear Strength; German Institute for Standardisation (Deutsches Institut für Normung): Berlin, Germany, 1997. 